\title{
Alegoría nostálgica de una derrota. Apuntes sobre Escuela de Guillermo Calderón
}

CONICYT - Pontificia Universidad Católica de Chile, Chile

javiera.larraing@gmail.com

Fecha de recepción: 19/11/2018. Fecha de aceptación: 17/02/2019.

\begin{abstract}
Resumen
En Escuela, Guillermo Calderón centra el eje de la acción en la educación paramilitar que reciben un grupo de militantes, opuestos a la Dictadura chilena, en una célula revolucionaria clandestina. Para ello, la dramaturgia construye puentes de filiación histórica que aúnan la tradición pasada de los hechos acontecidos en Dictadura con el acontecer presente de la realidad inmediata chilena. La autoría presenta una lectura desde la lógica de los afectos, que intenta diferenciar y categorizar los diversos actos de violencia armada; ya sean estos movidos por el odio o por el amor. De esta forma, Escuela surge como un agente que trabaja en el redescubrimiento y la redefinición del concepto de Estado bajo las consecuencias de la pasada Dictadura, centrando su eje dramático textual y performático en la fragmentación y la disolución de un referente social acefálico y disfuncional; y -por tanto- en la manera en que este criminaliza la violencia de aquellos que lucharon por recuperar la democracia. Así, Calderón establece relaciones subterráneas entre la naturaleza archivística de su texto y el acontecer político del país, mediante la reconstrucción cifrada del hecho memorístico en torno a las políticas de resistencia cívica militar en la Dictadura.
\end{abstract}

\section{Nostalgic Allegory of a Defeat. Notes on Escuela by Guillermo Calderón}

\begin{abstract}
In Escuela, Guillermo Calderón centers the action on the paramilitary education received in a clandestine revolutionary cell by a group of militants who oppose the Chilean Dictatorship. For this, the dramaturgy builds bridges of historical affiliation that combine the past tradition of the events that took place during the Dictatorship with the present occurrence of the immediate Chilean reality. The authorship presents an approach based on the logic of affects, which tries to differentiate and categorize the differents acts of armed violence considering whether they are moved by hatred
\end{abstract}

Palabras clave Escuela Calderón revolución violencia dictadura afectos
Keywords

Escuela Calderón Revolution Violence Dictatorship Affects 
or love. This way, Escuela emerges as an agent that works in the rediscovery and redefinition of the concept of State under the consequences of the last Dictatorship. Its dramaturgical and performative construction are, therefore, focused on the fragmentation and dissolution of a headless and dysfunctional social referent, as well as on the way in which it-consequently-criminalizes the violence of those who fought to recover democracy. Thus, Calderón establishes underground relations between the archival nature of his text and the political events of the country, through the encrypted reconstruction of an act of memory regarding the political actions of civic military resistance in the Dictatorship.

Cualquier acción de resistencia de parte de grupos extremistas, obliga a las fuerzas armadas a adoptar las más drásticas sanciones, no sólo respecto de los agresores sino que también en contra de quienes permanecen detenidos o sometidos a arresto domiciliario y vigilancia. Las fuerzas Armadas y de Carabineros serán enérgicas en el mantenimiento del orden público, en bien de la tranquilidad de todos los chilenos. Por cada inocente que caiga serán ajusticiados 10 elementos marxistas indeseables, de inmediato, y con arreglo a las disposiciones que el Código de Justicia Militar establece en los tiempos de guerra.

Bando № 30 de la Intendencia de la Provincia de Cautín, Temuco

(17 de Septiembre de 1973)

En el marco de la curatoría 'Memoria 1973-2013', organizado por el Festival Internacional Santiago A Mil (FITAM), que conmemoraba los cuarenta años del Golpe Militar, Guillermo Calderón (Chile, 1971) estrena Escuela en enero de 2013 en el Teatro de la Universidad Católica. En el elenco participan: Luis Cerda, Andrea Giadach, Camila González, Francisca Lewin y Carlos Ugarte, si bien en el estreno, en vez de Andrea Giadach, actuó Trinidad González, quien participó durante la primera temporada de la obra; María Paz González continúa en la Asistencia de Dirección y Loreto Martínez en el Diseño. En este montaje, el dramaturgo y director centra su fábula en la educación paramilitar que reciben un grupo de militantes chilenos opuestos al régimen, en una célula clandestina ambientada en los 80. El grupo está compuesto por Fidel -quien se convierte en el instructor Zeta, experto en armas y municiones, encargado de enseñarles al colectivo el cómo disparar-; Alejandra -que asume el rol de María, la instructora, tiene como misión dar cuenta de las bases ideológicas y teóricas de cómo opera el capitalismo que intentan combatir-; Ernesto -que se presenta como Equis, instructor en artes conspirativas de las células clandestinas-; Haydeé -quien asume el rol de la instructora Marcela, especialista en las repercusiones de la guerra psicológica que el régimen ocasiona en los sujetos reprimidos por la Dictadura y en la información secreta que se encuentra en el "Libro Blanco del Cambio de Gobierno en Chile"-; y por Carmen, quien, convertida en Tamara, instruye al grupo acerca de artefactos explosivos.

Calderón comenzó la escritura de esta obra, a partir de notas mentales que constituyen ideas, apuntes, recuerdos personales y opiniones sobre algún tema, como él mismo indica:

me siento cómodo pensando que la memoria se construye, que se vuelve a escribir cada vez que uno recuerda. Cuando hago una obra de teatro, cuando escribo, estoy escribiendo memorias. Yo construyo mi propio pasado como me 'conviene', evidentemente, pero a la vez entro a un territorio que está en disputa, porque hay diversas versiones en juego. (González, 2013: 12) 
Frente a esto, Escuela sigue la misma lógica de Villa+Discurso (2011), su obra anterior, aquella que persigue presentar un teatro de las ideas; pero radicalizándola.

Si en Villa+Discurso Calderón pretendía problematizar las formas de representación de la memoria, en Escuela (2013) retrocede hacia la memoria misma, hacia el acto de recordar en sí porque -en esta obra- hay una intención por rescatar una historia olvidada, la historia de aquellos que debieran ser recordados como héroes - por haber luchado en contra de la Dictadura- pero han sido borrados del relato oficial. Así Calderón (en González, 2013) declara que:

\begin{abstract}
el pasado se recuerda y se escribe. Cada vez que se recuerda se está volviendo a escribir esa memoria. Por lo tanto, las diversas memorias son distintas, aunque con el tiempo se impone socialmente un relato hegemónico. Ese relato es lo que se disputa. En Escuela, por ejemplo, estoy contando una historia del pasado. [...] Yo elijo recordarla así, y eso crea una memoria particular, y al mismo tiempo crea una idea de memoria que está entre la acción y la realidad. Me gusta ese potencial provocador que puede tener el teatro. [...] Se crea un sentido de comunidad, porque mucha gente comienza a pensar lo que tú piensas. Algo pasa en el escenario que hace que tus ideas cobren vida, adquieran un significado y se multipliquen. Cuando el teatro está lleno, siento que no estoy solo; obviamente, funciona como una droga, y uno quiere más. En el teatro se crea una comunidad en la memoria. (12-13)
\end{abstract}

A modo -tal vez involuntario- la obra se vuelve un homenaje honesto y sencillo frente a aquellos hombres y mujeres que la Historia oficial no ha querido recordar. Por ello, el hecho que los cinco actores salgan con capuchas a lo largo de todo el montaje-capuchas que jamás se sacarán- puede ser leído como una declaración de principios desde la dirección, como una manera de replicar desde la construcción visual y estética de la escena que como espectadores/ciudadanos no conocemos quiénes son estos hombres y mujeres que formaron parte del sueño revolucionario y que intentaron-sea desde el amor, la ingenuidad o la lucha armada como plantea la obra- hacer de la nación chilena un país más justo.

Calderón entiende que hablar de la memoria, es hablar de la Historia. En este caso, de aquella que ha sido silenciada en pos de un (falso) relato de unidad y reconciliación. Para Andreas Huyssen (2007), este olvido no es azaroso, sino que responde a los intereses conscientes de los sujetos y de la sociedad en que estos se desenvuelven:

A través de la actividad de la memoria, [...] la mirada museística expande el espacio cada día más encogido del presente (real) en una cultura de amnesia, obsolescencia programada y flujos de información cada vez más sincrónicos e intemporales, el hiperespacio de la era de autopistas informatizadas que se avecina (72).

Escuela propone el rescate de una memoria utópica, sosteniendo una batalla discursiva que instala la palabra de los sujetos residuales que la Democracia quiso dejar atrás, oponiéndose a la cultura de la amnesia.

Aquí -por consecuencia- las principales preocupaciones de la dirección de Guillermo Calderón se encausarán en torno a lógica de los afectos que rodea -paradójicamente- cuestiones como la violencia y la lucha armada, entendidas como actos de ternura y de amor; en torno a la transmisión de ideas sobre una causa ideológica y sobre el trabajo de la voz como vehículo de transmisión de estas ideas y afectos hacia el espectador. 


\section{De afectos, de pérdidas y de revueltas}

Sirva -en este punto- abrir un paréntesis para aclarar la diferenciación conceptual entre afecto y emoción. En cuanto a los afectos, no hay una teoría homogénea, sino variadas teorizaciones. Para Ana del Sarto:

afectos refieren a las capacidades corporales de afectar y ser afectado o al incremento o disminución de la capacidad de un cuerpo para actuar, captar y conectarse [...] son las facetas más ilustrativas de una subjetividad-en-procesode-transformación, de una subjetividad dislocada, de una subjetividad en retirada aunque activa (2012:47-51).

Las emociones no están suscritas a subjetividades ni parcelas ideológicas de pensamiento, sino al trabajo de concientización de un sentimiento:

Thought emotions can exist without consciousness and grow out of aspects of the proto-self, feelings begin when emotions rise to awareness, when the state of the body begins to register consciously in the mind [...] Put another way, feelings is how we register and interpret emotions, and consciousness begins with the 'feeling of a feeling (Blair, 2008: 68).

Las emociones son cruciales para comprender la naturaleza de los sentimientos en el trabajo actoral; mientras que los afectos son vitales para entender las subjetividades ideológicas que sostienen toda obra de arte, y-por lógica- de toda obra de teatro.

De acuerdo a esto -y cerrado el paréntesis-, para Michael Hardt (1999), la teoría de los afectos se enmarca dentro de una laborinamterial, que asume una posición dominante con respecto a otras formas de representación dentro del entramado del capitalismo de mercado. Su fuerte vínculo con la posmodernización social mercantil, es -al mismo tiempo- una potente posibilidad de subversión y autonomía frente a esta, al utilizar su poder biopolítico para revertir los imperativos mercantiles del duelo (89-90). Así, en palabras de Hardt, la mercantilización económica ha mermado la labor inmaterial de los afectos, puesto que el sujeto se relaciona con objetos y situaciones, pero desde una lógica de consumo desprovista de emociones para los sujetos sociales. La pérdida colaborativa de la función afectiva se configura en Escuela a partir de la derrota, pero que aún no deviene en escena, puesto que los personajes que asisten a esta célula clandestina no saben que la lucha popular armada del pueblo que ellos representan no prosperó. Aquella carga de derrota afectiva es entregada por los espectadores; son ellos quienes completan la lectura de la obra al leer las claves memorísticas en que esta se inscribe.

Sobre escena, la dirección articula los cuerpos de los actores cual actantes que no se apertrechan desde una mirada documental, sino desde la encarnación de la lógica del monumento en sus cuerpos, batallones de resistencia en contra de la pasada Dictadura, pero desde una mirada afectiva que no se erige desde metáforas, sino desde la realidad, desde un lenguaje concreto y directo. Ellos son el recuerdo encarnad; ellos son el brazo armado en contra del olvido de la muerte. Por tanto, en ellos no hay espacio para la sustitución metonímica:

MARÍA. Queremos luchar. Y crear. Un poder que sea popular. Popular. El poder simple del pueblo. No queremos someter a nadie. Queremos. Queremos dignidad, queremos comida. Estufita en invierno. Queremos ir al mar. Queremos libertad para vivir y para estudiar. Queremos paz. Paz. Pero para eso falta mucho (Calderón, 2013: 61). 
Ellos -aquellos que conforman la contrarrevolución de avanzada que Calderón propone- no apuntan a la mercancía anacrónica y museizada de los afectos; ya que ellos son -en sí mismos- la supervivencia encarnada del objeto que se ha vuelto obsoleto, del guerrillero que se ha convertido en residuo de la memoria.

Así: "La paradoja que instala el andamiaje de la memoria propuesta por Escuela, pone en cuestionamiento la consigna de entender la violencia, ya sea física o armada, como un afecto propio del odio, pues en la violencia del revolucionario no habría más que amor" (Larraín, 2015: 20). He aquí, que -sin la pretensión del cliché comercial- la figura del Che Guevara, epítome de la revolución armada latinoamericana ${ }^{1}$, resuena con fuerza como una lectura paralela a esta obra. En su diario de vida escribe:

déjenme decir, con el riesgo de parecer ridículo, que el verdadero revolucionario es guiado por un fuerte sentimiento de amor. Es imposible pensar en un revolucionario auténtico sin esta cualidad (Anderson, 1997: 636-637).

El afecto como acto de amor revolucionario se encuentra explícito en Escuela, en las palabras de María/Marcela, quien advierte que si ellos, el brazo armado del pueblo, retienen a agentes militares como cautivos no los torturarán ni los matarán de hambre, porque ellos no hacen una guerra sucia, hacen una guerra limpia. Pero, en las consignas de esta célula de educación paramilitar clandestina, también descansa el odio y el miedo -baluartes del aparataje militar-; porque, como bien indica Zeta, sin ellos es imposible disparar a matar y cuando se mata al enemigo, se siente -en parte- un alivio.

La violencia -como arma dentro del campo de batalla-consignada en un arma que se dispara o en una bomba que explota. forma parte del discurso biopolítico de los afectos y se opone -en ocasiones de manera tajante- a: "la política actualmente hegemónica en América Latina [que] se esfuerza por 'poner punto final' a la 'fijación del pasado', la tradición de los que fueron derrotados para que el mercado de hoy pudiera instalarse no puede darse el lujo de vivir en el olvido" (Avelar, 2000: 286). En razón de ello, a través de las distintas clases que componen Escuela, Calderón se enfrentaría a la crisis del arte por transmitir la experiencia traumática y el relato de los sujetos borrados por la Historia. Tras el intento -en parte fallido- de la mercantilización postdictatorial por borrar el pasado, esta prefirió -gracias a los Gobiernos de turno- encapsularlo bajo diversas formas de representación, como el documento, el monumento o el archivo, con el fin de distanciarse y oficializarlo bajo la intención metafórica del punto final.

Calderón declara que durante el proceso de ensayos, las configuraciones afectivas de esta obra fueron claras (González, 12-13). Siempre se entendió esta escuela de resistencia como un acto de amor, de afecto desinteresado, de aquel que está dispuesto a sacrificarse para instalar las demandas del pueblo, para ganar la batalla popular, como cuenta una de las encapuchadas:

MARCELA. Entonces el Dani le saca el seguro, se activa, se da vuelta para correr, levanta la cabeza y ve que viene gente caminando. Entonces vuelve y trata poner el seguro pero no le resulta. Entonces, cuando se da cuenta de que ya no alcanza, la toma, se la pone aquí, la abraza y explota (Calderón, 54).

Desde un principio, los actores supieron que hechos como este, no eran ficticios; sino reales, pues 'el Dani' (cuyo nombre verdadero era 'el Jano') fue un compañero de dieciséis años de Jorge Mateluna² que murió tras la explosión de una bomba que él portaba. Pese a que un relato como este, tiene no solo una carga afectica clara, sino también un componente emocional importante, Calderón destierra la emocionalidad
1. Slavoj Zizek advierte -muy lúcidamente a este respecto- que no hay que cometer el error de pensar en una cristianización del Che o del sujeto revolucionario en sí; pues la paradoja no descansa en dicha acción -como tampoco lo propone Calderón, quien está lejos de presentar al encapuchado como un mártir o un santo cristiano; ya que lo que realmente se presenta es una cheitización de la figura de Cristo, como imagen occidental-y universal-del sacrificio individual en pos de la instauración de un discurso de lucha y cambio social que apela a un colectivo humano. Al final de cuentas, la famosa frase del Che-que a estas alturas ya resuena como eslogan publicitario de una multinacional-: 'Tienes que endurecerte, pero sin perder la ternura', no dista mucho del llamado de Cristo a sus seguidores -en el Evangelio de San Lucas (14:26)- que si no están dispuestos a aborrecer a su padre, madre, hijos y hermanos, no pueden ser sus discípulos, quien no quiera sacrificarlo todo no puede amar ni hacer la revolución.

2. Jorge Mauricio Mateluna Rojas (1974) será el protagonista de la próxima obra de Calderón, titulada Mateluna (2016) en su honor. Esta metaobra describe el horror y la injusticia del sistema judicial chileno en torno a la figura de Mateluna, ex-guerrillero del Frente Patriótico Manuel Rodríguez (FPMR) que actualmente se encuentra preso y condenado a dieciséis años de cárcel por un asalto bancario que no cometió, en la comuna de Pudahuel; en medio de una serie de irregularidades tanto de la Policía como de la Fiscalía que estuvo a cargo de la investigación. 
desde los actores en escena. Estos deben contar la historia del Dani-y otras similares que se referencian en la obra- como si estuvieran recitando una receta de cocina, como si estuvieran impartiendo una lección pedagógica.

Son, entonces, los espectadores, los únicos encargados de incorporar la clave afectiva dentro de la obra; ellos son los interpelados no solo a emocionarse, sino también a entender afectivamente -como contraparte del relato experiencial- aquel acto de memoria y resistencia que significa Escuela, como Calderón declara, el teatro se vuelve -de este modo- un acto colectivo:

Porque cuando haces una obra descubres cosas que sentías y que no necesariamente sabías que sentías. Y, al exponerlo en el teatro, te completas con la reacción del público. Se crea un sentido de comunidad, porque mucha gente comienza a pensar lo que tú piensas. Algo pasa en el escenario que hace que tus ideas cobren vida, adquieran un significado y se multipliquen. Cuando el teatro está lleno, siento que no estoy solo [...] Por ejemplo, cuando ves que en el escenario están enseñando a usar un arma, te sientes obligado a decir algo, a quedarte callado, a aplaudir, a escandalizarte, a reírte. Viene una sensación de incomodidad, porque no sabes qué piensan los demás. Esa secreta perturbación, que obliga a negociar lo que uno siente con lo que uno puede expresar, es para mí una forma -mínima, pero significativa- de recrear lo que significó vivir la historia. (González, 2013: 12-13)

Pero si bien, esta es una obra plagada de afectos; estos solo pueden encontrarse escénicamente en el plano de la palabra material, aquella palabra dicha por los actores, como si se encontrarán realizando una exposición académica frente a una audiencia que escucha atenta cómo hacer la revolución. Como comenta Camila González, actriz del montaje:

En Escuela no había derecho a emocionarse. Cuando nos surgía [a los actores] el ímpetu de decir una idea como 'más teatral', él nos decía ‘bajen, bajen'. [...] Pero sin emocionarnos, si nos emocionábamos o afectábamos, matábamos la idea. El punto era realmente empoderarse de la idea, tomarse el tiempo, para informarla, para educar (en Larraín, 2014: 4).

Las emociones y los afectos no deben ser actuados o representados; estos surgirán a partir de la experiencia de la propia escuela, de la palabra enunciada. La clave afectiva no está dada en el cómo se nos cuenta el relato, sino en el relato en sí mismo, en el acto de recordar y presenciar esta revolución violenta hecha desde el amor.

\section{Configuraciones de lo metateatral, la escuela como teatro}

Para Calderón esta obra fue un proceso de descubrimiento con los actores. Era la primera vez que no escribia una obra para determinados actores en particular con los que estaba trabajando, puesto que si bien a muchos de ellos, los conocía de su paso por al Escuela de Teatro de la Universidad de Chile o como profesor en la Escuela de Teatro de la Universidad Católica; no había compartido con ellos previamente en otros trabajos. Tal vez, por dicha razón, terminaría por desechar su ideal inicial; una obra de corte más dramático, con personajes definidos y una fábula que relatar. Pasadas un par de semanas de ensayo, Calderón sintió que la obra no estaba funcionando, ya que no podía transmitirse aquella noción pedagógica de aula que quería transferir hacia el espectador. Es así, que decidió incorporar una serie de monólogos y pensar cada uno de estos como una clase de una escuela paramilitar clandestina en los 80: métodos conspirativos, marxismo, el libro blanco, cómo manipular un arma, cómo poner una bomba (González, 2013). 
La escuela se articula como la instalación de un segundo escenario metadramático sobre la escena; siendo el primero la obra de teatro en sí. Esto ocurre, pues cada uno de los actores en escena, asumirá otra-identidad cuando les toque instruir a sus compañeros. Esta acción queda clarificada porque se intercambiarán un único par de lentes oscuros de sol que cada uno de ellos usará cuando cumplan su rol como instructores. De hecho, en este juego de roles, se encuentran el nivel metateatral 'the role playing within the role' que consiste -según Hornby (1986)- en la estrategia del rol dentro de otro rol, vale decir el actor representa un personaje, quien, a su vez, representa otro personaje, generando dos niveles de ficción. Este segundo nivel puede ser de manera directa -como en Neva o Diciembre- o un poco más indirecto, como se aprecia en Escuela. Aquí, los actores trabajan en un doble nivel que alternan sucesivamente a lo largo de todo el montaje; son estudiantes de esta escuela y son instructores de la misma. Mientras se encuentran en su condición de alumnos, estos se muestran -a veces- ansiosos, temerosos o dubitativos; pero cuando asumen su rol de instructor actúan con absoluta seguridad.

La clase se configura -consiguientemente- como un segundo escenario, como un segundo pequeño teatro en donde se alecciona y enseña la revolución. Como se mencionó en el apartado anterior, mientras los encapuchados instruyen no hay derecho a emocionarse, pues se está enseñando y la lección debe ser lo más clara posible tanto para los demás actores como para los espectadores. Camila González recuerda -a este respecto- que Calderón comentaba en los ensayos:

La mejor actuación es la mejor clase, entrega de información. Ustedes están exponiendo, haciendo una clase. ¿Cómo saber si lo están haciendo bien? Lo hacen bien, si el otro entiende a cabalidad eso que ustedes le están enseñando (en Larraín, 2014: 3)

Ernesto, convertido en Equis, deja esto bastante claro. No solo alecciona sobre qué es la información compartimentada, sino que da cuenta de la instancia pedagógica en que se encuentran:

EQUIS. Afuera hay un ejército. Un ejército que nos quiere matar.

ALEJANDRA. ¿Ahora?

EQUIS. No. Ahora no. En general.

HAYDÉE. Ah.

ALEJANDRA. Chuta. (Equis saluda a todos. Besos. Abrazos).

EQUIS. Sí. Mira. Todo de nuevo. Afuera hay un ejército que nos quiere matar. Y esta es una escuela. Una escuela. Por eso vamos a partir enseñando lo más importante. Las técnicas conspirativas. Conspirativas. Porque nosotros conspiramos. Sí. A todos nosotros, a ti, a ti, a mí, a usted. A todos nos andan buscando. Nos quieren matar. Por lo tanto nuestro trabajo es clandestino. Secreto. Es tan secreto que no nos sabemos nuestros nombres y aquí no nos podemos ver las caras. Porque qué pasa si ellos agarran a uno de nosotros después nos agarran a todos. Ya. Y es triste morirse. Pero es mucho más triste que no logremos nunca la victoria final [...] Nuestra organización está construida con el mismo principio: la compartimentación. Si a ti te detienen y te torturan y te quiebran, nadie más cae. Porque tú no sabes nada del resto de nosotros. Somos compartimientos aislados. Ni siquiera nos has visto la cara. Esta casa. ¿Dónde estamos? [...] No sabemos. ¿Por qué? [...] Nos marearon. A todos (las cursivas son mías). (Calderón, 13-14) 
Calderón no solo pretende testimoniar las voces -reales y pragmáticas- a través de los actores en escena, sino que también busca cuestionar las filiaciones materiales que presenta la lucha armada, gracias a una serie de inquietudes; que versan sobre el posicionamiento de la burguesía en la lucha popular, el coste económico, la humanidad socialista versus la barbarie militar, la inmolación en pos de la causa y el rol de la violencia como elemento tangencial de lucha.

Así, los procedimiento metadramáticos son constantes, como cuando María -quien instruye sobre el rol del Estado proteccionista del capitalista- le pide a Haydeé que la ayude a graficar a Guacolda, la mujer trabajadora explotada por su patrón, y a Fidel para hacer de su amigo:

MARÍA. Así que eso es lo que te toca. Cinco. ¿Pero cinco? ¿Tan poco? Te podría haber pagado mucho más, pero no quiere. ¿Por qué? No quiere no más. Además necesita una casa en la playa. Para eso puso la fábrica. Es el dueño del capital. Entonces después de la jornada de catorce horas, tú sales de la fábrica. Y caminas. Con los dedos todos pinchados por la aguja. Y para pasar la angustia te compras un vino en caja y te lo vas a tomar a una plaza. $Y$ te encuentras con una amigo. Hola Juan Carlos. Hola Guacolda. Y le cuentas lo que te pasó. Y le muestras los tres pesos que te quedan.

HAYDÉE. Mira. Me quedan tres pesos.

FIDEL. ¿En qué te gastaste el resto?

HAYDÉE. Me gasté los otros dos en el vino en caja.

FIDEL. ¿Cuánto te pagan?

HAYDÉE. Cinco.

FIDEL. Pero Guacolda...

MARÍA. Exacto. Y tu amigo te mira, y te dice: te robaron la plusvalía.

FIDEL. Guacolda... te robaron la plusvalía.

HAYDÉE. ¿Cómo?

MARÍA. Exacto. La plusvalía. ¿Y qué es la plusvalía? ¿Qué es la plusvalía? La plata que sobra. (9-10)

Esta serie de juegos representacionales funcionan como una estrategia que dinamiza la exposición pedagógica de cada uno de los actores,; quienes son muy conscientes -en todo momento- que están enseñando/educando/aleccionando en una escuela; buscan -conforme a ello- prácticas que ayuden a dinamizar su discurso e incluyan más participativamente a sus estudiantes.

Para conformar esta escuela los actores -en conjunto con Guillermo Calderón y María Paz González-se documentaron ampliamente y -como se indicó- recibieron la visita de antiguos participantes y miembros de células revolucionarias chilenas, entre ellos, Jorge Mateluna. Estas clases sirvieron para que los actores pudieran adentrarse en el mundo de la militancia; para que ellos asistieran a la escuela, para después poder replicarla en un acto de duplicación metateatral. En una de estas visitas, Jorge Mateluna les enseñó cómo tomar y usar un arma; y los actores -que se encontraban en un círculo a su alrededor-naturalmente 
se acercaron a él para poder ver mejor el procedimiento que estaba llevando a cabo. Calderón, que estaba fuera de este círculo, vio en este gesto la intención y el sentido de toda la obra; es por ello que Escuela se construyó tal como su nombre lo dice: como una escuela donde se va a aprender, donde se entrega información y se educa -en este caso- no solo a los compañeros del elenco, sino también -de paso- al público.

Es por esta razón -como se señaló- que los actores en escena se desenvuelven desde el registro informativo y/o expositivo. La escuela se transforma en el teatro, en una pedagogía letal -citando a Opazo (2011). Se intenta informar -por una parte- de aquellos relatos que nadie conoce, puesto que la historia oficial no solamente los ha omitido, los ha borrado del mapa histórico de la nación. Calderón así declara:

\begin{abstract}
Yo creo que es importante recordar este lado porque ha sido un poco silenciado y ha sido intencionalmente postergado. Entonces me parece que es fundamental a la hora de recordar la dictadura. Ahora, a partir de las manifestaciones estudiantiles en mucha gente ha existido el consenso de que la transición fue injusta, decepcionante y me parece importante al recordar la dictadura, recordar justamente el momento en donde existe la posibilidad de votar o no en el plebiscito. Y la historia oficial que es la historia de que el gobierno de la dictadura cae por un plebiscito donde gana el No, se dice que derrotamos la dictadura con un lápiz. Y cada vez queda más claro que en realidad la dictadura nunca fue derrotada. (Gutiérrez, 2013)
\end{abstract}

Rescatar las vidas reales de jóvenes como 'el Dani' que se inmolaron por una causa -la lucha contra la Dictadura- que el país olvidó; es el motor principal de esta intención expositiva que Escuela persigue. Pero no es la única, ya que -por otra parte- la obra no solo busca informar, sino también instruir. Casi, en un acto antropológico, los actores reconstruyen este saber olvidado, esta escuela de resistencia.

Calderón -para conseguir esta reproducción particular de escuela- trata de vaciarperformativamente la escena de afectos, al menos en el plano interpretativo de los actores, pero no así en aquellos que puedan aflorar en los espectadores. Porque, pese a lo que comúnmente se piensa, los afectos no son mera emocionalidad irracional; más bien, todo lo contrario, ya que se emplazan en el campo de la ideología y la razón, poniendo a los sujetos en conflicto con sus propias filiaciones, creencias y prejuicios:

Affects refers generally to bodily capacities to affect and be affected or to the argumentation or diminution of body's capacity to act, engage, and to connect, such that autoaffection is linked to the self-feeling of being alive -that is aliveness or vitality (Clough \& Halley, 2007: 2).

Los afectos conducen a la acción y la reflexión, que es aquello que Calderón busca despertar en los espectadores. La escuela como buen proyecto pedagógico, cuestiona; y -en este caso- indisciplina. Educar para convocar la revuelta popular: "MARÍA. Organicen la vanguardia. Y eso hacemos. Estamos llamando a todo el pueblo a sumarse a la lucha [...] para convertirnos en la vanguardia nosotros tenemos que conducir al pueblo" (Calderón, 28-29); educar para revolucionar.

\title{
Cuando una capucha te tapa el rostro, la voz como protagonista
}

Para Marcela Sáiz, en la poética de Calderón:

La problematización sería más bien, la elaboración de un dominio de hechos, de prácticas y de pensamientos que a uno le parece que plantean problemas. Es decir, problematizar, es un modo de actuación del pensamiento, una actitud que permite 
tornar inseguro lo que damos por seguro, y que a diferencia de otras posturas, no busca hacer visible lo invisible, sino que hacer visible lo que, justamente por estar tan cerca de nosotros, no llegamos a percibirlo. (2013:24)

Este ejercicio de problematización sobre la memoria histórica ha estado presente -en mayor o menor medida- a lo largo de toda su obra. Este dominio de hechos, pensamiento y prácticas que Sáiz menciona están registrados en Escuela en la serie de monólogos y/o lecciones que cada uno de los actores expondrá a sus demás compañeros. Para ello, la claridad verbal, con la que las distintas lecciones sobre revolución armada son expuestas, debe ser primordial en la estructuración de la palabra hablada de los actores. Así, los motivos para ocultar sus rostros, quedan claros desde un comienzo:

MARÍA. Le digo lo siguiente. Yo escondo mi cara porque mi lucha es ilegal. Y tengo miedo de que me metan presa y me maten. Hay gente que muestra su cara porque no tiene nada que temer. Yo tengo miedo. Tengo miedo que me apliquen el genocidio [...] Debajo de esta capucha hay ideas políticas. Y esas ideas me dan dignidad. Yo podría estar en el cine. Podría estar enamorada. Podría estar jugando paletas en El Quisco. Pero estoy aquí, arruinando mi vida. (Calderón, 41)

Incluso ellos mismos -si caen como mártires- no podrán honrar el rostro de sus compañeros, pues el éxito de su revolución descansa en el secreto y en el sacrificio:

EQUIS. Quizás se enojen y te maten. Pero nosotros cuatro, los que quedemos vivos, vamos a seguir luchando. Y nos vamos a acordar de ti. Y cuando lleguemos al poder te vamos a pintar un mural con tu cara.

CARMEN. Pero no me van a conocer la cara.

EQUIS. Es verdad. Te vamos a pintar con la capucha puesta.

\section{CARMEN. Gracias.}

EQUIS. Y espero que todos ustedes hagan eso por mí. Pero por ahora lo más importante, hasta que no lleguemos al poder, es que nunca se sepa quiénes somos ni que estuvimos aquí. De hecho... Para mí esto es tan secreto, tan secreto, que no lo sabe ni mi compañera.

HAYDÉE. ¿Y ella dónde piensa que estás?

EQUIS. Ella piensa que estoy con mi amante. (52)

El sacrificio por la causa debe ser total, Calderón intenta plasmar cómo los participantes de estas guerrillas populares se jugaron por completo para luchar por su causa, por el pueblo, sacrificando por ello, sus familias, sus trabajos, su libertad y -por supuesto- sus vidas.

Con una puesta de diseño minimalista, compuesta por un piso de parquet, un par de sillas, una mesa y una pizarra donde se dibujará, se escribirán apuntes y se proyectarán imágenes que apoyen -tal como en una disertación escolar- las diversas clases que cada uno de los actores expondrá durante la obra, el énfasis está puesto en los intérpretes. Pero estos no se encuentran absolutamente visibles ante los ojos del espectador, puesto que sus cabezas están por completo cubiertas con capuchas, que solo permiten ver-tímidamente- sus ojos. El vestuario - de esta forma- entrega ciertas claves para leer la procedencia, la historia o el origen de los encapuchados. Algunos visten más formal, con ropas -en apariencia- más costosas, y otros llevan ropas más 
sencillas y cotidianas. Así, la decisión de ocultar el rostro con la capucha no solo no permite ver los gestos faciales de los actores, sino que pone a la voz como protagonista de toda la obra. Es a través de la voz, de la palabra dicha, que se comunicarán las ideas y se darán a conocer las historias de estos sujetos residuales de la historia nacional. Camila González recuerda a este respecto que el trabajo principal durante los ensayos consistió en el cómo exponer estas clases frente a los demás actores:

[Guillermo] nos decía que lo más importante era la manera en que nos expresáramos, teníamos que sacarnos esa cosa teatral que uno [como actriz] lleva por defecto. El objetivo era ser directo y claro, mientras más clara soy, más directa; mejor estoy haciendo mi clase. Hablar como si estuviera en un espacio íntimo de mi casa, hablando con unos amigos (en Larraín, 2014: 5-6).

Frente a esto, Luis Cerda (2017) agrega que la obra es compleja, en tanto carece de una postura estricta, por lo tanto permite el espacio de discusión o genera cierta controversia. En la estructura se advierten ciertos matices, una carencia de clímax que es de cierta forma rupturista para la típica estructura aristotélica de las obras. Por eso, era muy importante que los actores se volvieran expertos en los temas que debían enseñar, sin caer en sentimentalismos. La emoción entonces no se actúa ni se muestra, sino que se encuentra contenida en la palabra dicha, en el acto de enunciación vocal ejecutado por los actores.

Calderón (en Gutiérrez, 2013), interrogado por la dificultad de trabajar con los actores encapuchados durante todo el montaje, comenta:

Para mí era súper importante hacer eso. Porque justamente esta gente está invisible y como esas personas nunca fueron considerados como luchadores por la democracia, sino que fueron considerados como terroristas o extremistas, ellos viven en una situación actual de secreto porque tú eres combatiente para toda la vida. A pesar de los años esto sigue siendo un secreto, la identidad todavía no se revela porque de alguna forma la dictadura sigue impuesta. Y también porque me parece que es un tema doloroso, incómodo y la obra tiene que enfatizar eso. Por último las escuelas político-militares eran así, encapuchados. Por lo tanto hay un tema con la identidad. Porque la identidad desaparece como persona y te transformas en un combatiente más de una causa. Y eso es muy bonito, porque se convierte en un colectivo donde la identidad desaparece para ser algo mucho más grande que él.

La capucha se transforma en un gesto político que busca reivindicar la lucha armada de aquellos que dieron batalla contra la Dictadura activamente y que la historia oficial decidió recordar como criminales -encarcelándolos en Democracia- en vez de como héroes. Por esta razón, la emoción en los actores anularía las ideas y la información que se entrega. Para Isabel Baboun:

esto responde a un contexto político, el de ocultar cualquier signo de identidad como medida de protección aunque también, el encapucharse funciona como estrategia escénica de montaje, metodología teatral, como una 'clandestinidad actoral', una forma de postergar los despliegues expresivos del rostro para potenciar cualquier manifestación sobre los cuerpos de los actores y así atender a la emoción desplegada en su máxima expresividad. (2016: 96)

La obra se acerca así, estrechamente a la propuesta de un teatro didáctico, que busca ser claro y directo, desprovisto de cargas emocionales por parte de los actores, pero repleto de subjetividades afectivas en el discurso transmitido por medio de la palabra. Esta estrategia consigna una fuerte construcción ideológica, en la que son los espectadores quienes deben realizar el proceso afectivo, racional y emocional. 
Los afectos son transmitidos -de este modo- por medio de la palabra, siempre bajo la misma indicación por parte de la dirección, tal como cuenta Camila González (en Larraín, 2014):

Ser claro, eficaz con el lenguaje, respetar la puntuación eran cosas esenciales para Guillermo. En Escuela igual cada uno tenía como una 'pequeña personalidad' con su personaje. Pero lo vital era ser didáctico y directo con la clase que exponías. El objetivo era instruir, instruir, instruir (8).

Se aboga por una voz naturalizada, sin artilugios de proyección vocal o con claras marcas denotativas; para esto se utilizan -nuevamente- micrófonos inalámbricos. De esta manera, los actores no deben impostar ni forzar ni proyectar la voz para que sean escuchados en la última butaca del teatro. Otra vez Calderón propone una apuesta casi cinematográfica al momento de abordar la escena. Esta estrategia predispone también la relación con el espectador, si se considera que:

Theatre sound presupposes our emotional and cognitive engagement: our sensual immersion in the event and reflection on its possible meaning. But what appears as a tidy resolution, a dialectic unity of opposities that build the dramatic story, is undone by a series of constantly renewed dichotomies in performance. It is the dichotomies of sound and meaning, speech and language, time and space, body and sense, performance and text, which lie at the core of theatre theory and practice, layered with ancient history and contemporary urgency. (Ovadija, 2016: 12)

El espectador se enfrenta a cada una de estas clases de la misma manera tan directa en que los actores entregan la información y es movilizado -gracias a ello- para completar un intercambio guiado por el giro afectivo.

Por medio de este relato directo y asertivo, la discursividad ideológica de la obra es clara y no da margen a interpretaciones. Con profusa realidad, Calderón instala a modo de postal, el proceder de estas escuelas paramilitares de los 80 . Y con la ejecución de un lenguaje expositivo, conciso y directo por parte de los actores, los afectos son movilizados hacia el público sin metáfora alguna de por medio, entendiendo -a su vez- que el afecto como acción de subjetividad ideológica no es más que: "otro nombre para la variación continua que caracteriza los encuentros infinitos entre los cuerpos, y los desplazamientos y transformaciones, constituciones y disoluciones, que de ellos resultan" (Beasley-Murray, 2010: 128). Porque así, cuando esto ocurre, los espectadores se ven movilizados e interpelados, deben tomar una postura crítica frente a aquello que están viendo y dicha movilidad -en ocasiones- puede ponerlos en crisis, siendo esto último una de las tareas que Calderón propone en esta obra.

En todo momento, dado el protagonismo de la voz dentro de la puesta en escena, como una forma de honrar el relato de los revolucionarios, se cuida respetar la puntuación de los textos (las comas, los punto seguidos, los puntos apartes), porque estos serán aquellos que les entregarán una estructura formal a los actores para poder trabajar la materialidad del enunciado vocal, ya que este es muy importante en la poética escénica de Calderón, sobre todo si se tiene en cuenta que:

Vocal sound brings a pure energy, an energetic fields of perpetual becoming [...] It acquires materiality and earns dramaturgical currency exactly by dissociating itself from mere verbal meaning. It succeeds at turning text into performance just ti the extent that it succeds in betraying its denotative function. Furthermore, since a temporal event sound/vocal utterance can never be repeated in the same shape twice, it shapes nothing but an inmediate non-representational performance. (Ovadija, 2016: 55) 
La puntuación sobre la que trabajan los actores no es en lo absoluto azarosa, sino que responde a una clara intención del dramaturgo -y director- por delimitar el trabajo textual en una serie de niveles: ideológicos, actorales, escénicos; que al conjugarse en la puesta en escena demarcan un claro devenir rítmico que instala una musicalidad vital en el montaje.

Pero dicha sonoridad musical no solo se instala en la rítmica puntuacional de la palabra hablada, sino que también en la serie de canciones que los actores cantarán en vivo acompañados de una guitarra. Para Silva, Vilches y Orellana, esta selección musical en Escuela:

te transporta a cierta época debido a la melodía y al contenido político/social cantado por personas con capuchas en sus rostros, estableciendo una relación con cierto tiempo de opresión y resistencia, y vinculándolo así con la dictadura como la historia más cercana que abarca dichos contenidos, donde podemos identificarlo a través del sonido y la imagen propuesta (2017: 56).

Calderón decide no utilizar canciones chilenas de índole popular -y muy conocidas evidentemente por los espectadores- puesto que, como él advierte, dicha decisión hubiera sido un poco predecible e instalaría a la obra en un plano un tanto superficial. En vez de ello, utiliza canciones de grupos guerrilleros de Argentina y Uruguay, y canciones de la Guerra Civil Española y de la Revolución Sandinista: 'Himno Montonero; ' 'La Tumba del Guerrillero', 'Comandante Carlos Fonseca' e 'Himno de la Unidad Sandinista' de Carlos Mejía Godoy; 'Himno Tupamaro; 'Soldadito Boliviano' de Paco Ibáñez; 'Por allí viene Durruti'; y ‘La Balada de Ho Chi Minh' de Ewan McColl. El uso de estas canciones amplían la panorámica de la obra, estableciendo un guiño hacia las mismas escuelas de guerrilla que el montaje quiere documentar. Y además, funcionan a modo de interludios musicales que se intercalan entre las distintas clases que exponen el grupo de guerrilleros, potencian la propuesta didáctica que la obra en sí propone; y aportan a la rítmica puntuacional delimitada por el trabajo actoral. Pero, por sobre todo, estas canciones instalan-como ya se mencionaba- un aurea de ingenuidad y de candidez al acto de la guerrilla revolucionaria en sí, consignando la violencia armada como un acto de amor.

El desenlace de la obra termina por instalar -de hecho- este acto armado desde la complicidad de la fiesta y del regocijo, desde la lógica de los afectos. El vestido de gala de María no era un mero signo antojadizo, sino una pista. Los cinco estudiantes/instructores se han reunido en las últimas horas previas al Año Nuevo, para así poder ocultar el sonido de sus revólveres, que se confundirán con la algarabía de los fuegos artificiales. Calderón cierra la obra con un gesto escénico rotundo, al igual que en sus montajes anteriores. Ahora, con el fin de recordar que en la lucha contra la Dictadura -y en el sucesivo retorno a la Democracia- no solo hubo abrazos, sino que también balas. Cada encapuchado dedica su bala a alguna consigna o a alguien en particular, como 'el Dani'. Después de desearse Año Nuevo, repiten cual mantra budista: "El sí. El no. La misma huevá los dos. El sí. El no. La misma huevá los dos. El sí. El no. La misma huevá los dos. El sí. El no. La misma huevá los dos" (Calderón, 66), para proseguir con la ejecución de sus disparos. El sonido de las balas es absorbido y silenciado por las canciones de cumbia que suenan alrededor, en una grabación en off como correlato del Año Nuevo. Y, aunque el futuro inmediato que pesa sobre estos encapuchados guerrilleros se avecina de manera funesta, puesto que -como espectadores- conocemos qué les deparó la Historia. La peor batalla es la que no se libra, pues -como dicta este final- la revolución puede ser entendida como una canción de cumbia; la revolución es una fiesta. 


\section{Dibliografía}

"Anderson, J. (1997). Che Guevara: A revolutionary life. New York: Groove, 1997.

"Avelar, I. (2000). Alegorías de la derrota: La ficción postdictatorial y el trabajo de duelo. Santiago: Cuarto Propio, 2000.

"Baboun, I. (2016). Subjetividades afectivas en el Nuevo Teatro Chileno: Cristián Plana, Guillermo Calderón y Manuela Infante. (Tesis de Magister Inédita). Office of Graduate Studies, University of California Davis, United States.

»Beasley-Murray, J. (2010). Poshegemonía. Teoría política y América Latina. Buenos Aires: Paidós.

"Blair, R. (2008). The Actor, Image, and Action. Acting and cognitive neuroscience. New York: Routledge.

»Calderón, G. (2013). Escuela. Texto inédito facilitado por el autor.

"Clough, P., Ticineto \& Halley, J. (2007). The Affective Turn: Theorizing the Social. Durham: Duke University Press.

"Del Sarto, A. (2012, julio-diciembre). "Los afectos en los estudios culturales latinoamericanos. Cuerpos y subjetividades en Ciudad Juárez”. Cuadernos de Literatura (32), 47-51.

» Hardt, M. (1999). “Affective Labor”. Boundary (2), 89-90.

» Hornby, R. (1986). Drama, metadrama and perception. London: Bucknell University Press.

"Huyssen, A. (2007). En busca del futuro perdido. Cultura y memoria en tiempos de la Globalización. Buenos Aires: Fondo de Cultura Económica.

» González, D. (2013). “Guillermo Calderón, el dramaturgo de la memoria”. Revista PAT (56), 12. Recurso electrónico: www.revistapat.cl/numeros/PAT56/

» Gutiérrez, M. (2013, 18 de abril). “Guillermo Calderón: 'Cada vez queda más claro que la dictadura nunca fue derrotada’”. En The Clinic. Recurso electrónico: http://www.theclinic.cl/2013/04/18/guillermo-calderon-cada-vez-quedamas-claro-que-la-dictadura-nunca-fue-derrotada/

»Larraín, J. (2014, agosto). “La peor batalla es la que no se libra. La memoria histórica en Escuela de Guillermo Calderón". I Simposio de Estudios del Cono Sur LASA. Actores, demandas, intersecciones. Santiago, Chile.

»Larraín, J. (2015). “Claves en la poética dramatúrgica de Guillermo Calderón. Ideología, afectos y memoria en Clase, Villa + Discurso y Escuela". Creación, producción y educación en las Artes Escénicas del Siglo XXI. X Encuentro Teatral en Valparaíso, 2015. Valparaíso: Universidad de Playa Ancha.

» Orellana, C., Silva, C. \& Vilchs, J. de Luna. (2017). Lo biográfico, lo testimonial y lo documental como instrumento para la puesta en escena. (Tesis de Pregrado Inédita). Facultad de Arquitectura, Escuela de Teatro, Universidad de Valparaíso..

» Ovadija, M. (2016). Dramaturgy of Sound in the Avant-Garde and Posdramatic Theatre. Canadá: McGill-Queen's University Press.

"Sáiz, M. (2013). El teatro político de Guillermo Calderón. Teatro, Historia, Memoria 
en una poética de las ideas (Tesis de Magister Inédita). Facultad de Filosofía y Humanidades, Universidad de Chile.

» s/f. (2017, 2 de abril). “Escuela de Guillermo Calderón: 'La obra es importante, siempre va a ser contingente”". En Noticia Fundación Santiago a Mil. Recurso electrónico: http://fundacionteatroamil.cl/noticia/escuela-guillermo-calderon-la-obra-importante-siempre-va-contingente/ 